\title{
Bi-Metal Phosphide NiCoP: An Enhanced Catalyst for the Reduction of 4-Nitrophenol
}

\author{
Lijie Sun ${ }^{1}$, Xia Xiang ${ }^{1, *}$, Juwei $\mathrm{Wu}^{1}$, Chao Cai ${ }^{2}$, Dongyi Ao ${ }^{1}$, Jinling Luo ${ }^{1}{ }^{\circledR}$, \\ Chengxiang $\operatorname{Tian}^{1}$ and Xiaotao $\mathrm{Zu}^{2}$ \\ 1 School of Physics, University of Electronic Science and Technology of China, Chengdu 610054, China; \\ sunlijie09@std.uestc.edu.cn (L.S.); wu756070691@gmail.com (J.W.); aodongyi@outlook.com (D.A.); \\ luojinling0803@gmail.com (J.L.); tianchengxiangky@163.com (C.T.) \\ 2 Institute of Fundamental and Frontier Science, University of Electronic Science and Technology of China, \\ Chengdu 610054, China; ZChaoC@yahoo.com (C.C.); xtzu@uestc.edu.cn (X.Z.) \\ * Correspondence: xiaxiang@uestc.edu.cn; Tel.: +86-28-8320-2130
}

Received: 26 December 2018; Accepted: 9 January 2019; Published: 18 January 2019

\begin{abstract}
Porous phosphide $\mathrm{Ni}_{\mathrm{x}} \mathrm{Co}_{\mathrm{y}} \mathrm{P}$ composite nanomaterials are successfully synthesized at different $\mathrm{Ni} / \mathrm{Co}$ ratios $(=0,0.5,1$, and 2$)$ to reduce 4 -nitrophenol. The $\mathrm{X}$-ray diffraction and $\mathrm{X}$-ray photoelectron spectroscopy results demonstrate that the products are $\mathrm{CoP}, \mathrm{NiCoP} / \mathrm{CoP}$, $\mathrm{NiCoP}$, and $\mathrm{NiCoP} / \mathrm{Ni}_{2} \mathrm{P}$ when the $\mathrm{Ni} / \mathrm{Co}$ ratio is $0,0.5,1$, and 2 , respectively. The products exhibit different catalytic performance for reduction of 4-nitrophenol at room temperature. Among them, the pure NiCoP delivers a better catalytic efficiency with $k_{a p p}=677.4 \times 10^{-2} \mathrm{~min}^{-1}$ and $k=338.7\left(\mathrm{Lg}^{-1} \mathrm{~min}^{-1}\right)$, due to the synergy between $\mathrm{Ni}$ and $\mathrm{Co}$ atoms. The sequence of catalytic efficiency of different samples is $\mathrm{CoP}<\mathrm{NiCoP} / \mathrm{CoP}<\mathrm{NiCoP} / \mathrm{Ni}_{2} \mathrm{P}<\mathrm{NiCoP}$.
\end{abstract}

Keywords: phosphating cobalt nickel; reduction 4-NP; efficiency; hydrogenation

\section{Introduction}

In the past decades, water contamination has become an inevitable issue, and the use of unhealthy water is one of the most important sources of diseases [1]. Among these toxic effluents, 4-Nitrophenol (4-NP) is deemed to be one of the most ubiquitous organic contaminants in waste waters generated from agricultural and industrial production [2,3]. Therefore, many efforts are devoted to develop technologies for water purification, such as the utilization of polymeric membranes [4-7]. However, the chemical properties and toxicity of pollutants cannot be changed. And there is a broad consensus on the difficult detoxification of 4-NP by conventional water treatment due to its high chemical stability and resistance to microbial degradation which are attributed to the presence of a nitro-group in the aromatic compound [8]. Fortunately, 4-NP can be degraded to p-aminophenol (4-AP) by using the organic or inorganic catalysts $[9,10]$, such as polymeric membranes or metal catalysts. In addition, 4-AP is also widely used as a dyeing agent, photographic developer, corrosion inhibitor in paints, and anticorrosion-lubricating agent in fuels for two-cycle engines [11]. Therefore, it is of great significance to convert the hazardous 4-NP into a useful 4-AP by hydrogenation $[12,13]$.

Transitional-metal phosphides (such as $\mathrm{FeP}, \mathrm{MoP}, \mathrm{Co}_{2} \mathrm{P}, \mathrm{CoP}, \mathrm{NbP}$ and $\mathrm{Ni}_{2} \mathrm{P}$ ) have drawn attentions recently because of their excellent semiconducting, topological Weyl semimetal, novel magnetic and photocatalytic properties [14-20]. Different from nitrides and carbides, the phosphorus atom in transition metal phosphides is usually found at the center of a triangular prism, rather than residing in the interstitial spaces between metal host atoms. This is because that the atomic radius of phosphorus $(0.109 \mathrm{~nm})$ is larger than that of nitrogen $(0.065 \mathrm{~nm})$ or carbon $(0.071 \mathrm{~nm})$ [21]. Furthermore, since 
phosphides have more coordination unsaturated bonds than carbide and nitride, they have more phase states than carbide and nitride.

Recent studies have demonstrated that transitional metal phosphides present better catalytic effects for hydrodesulfurization, hydrodenitrogenation and hydrogenation [22,23]. For instance, Stinner et al. fabricated the MoP with better hydrodenitrogenation performance than $\mathrm{MoS}_{2}$ owing to the enrichment of Mo in MoP [24]; Song et al. designed $\mathrm{FeP} / \mathrm{SiO}_{2}$ as hydrodesulfurization catalysts [25]; Ibrahim et al. prepared the $\mathrm{Ni}_{0.3} \mathrm{MoP}$ catalysts, supported on $\mathrm{Al}_{2} \mathrm{O}_{3}$ as hydrodenitrogenation and hydrodesulfurization catalysts [26]. For the hydrogenation of 4-NP, phosphide materials exhibited remarkably high efficiency. Tian et al. prepared an $\mathrm{Ni}_{2} \mathrm{P} / \mathrm{Ni}_{12} \mathrm{P}_{5}$ bi-phase nanocomposite, and the obtained catalysts showed better activity with $k_{\text {app }}=50.04 \times 10^{-2} \mathrm{~min}^{-1}$ [8]; Wei et al. synthesized an urchin-like and hollow $\mathrm{Ni}_{\mathrm{x}} \mathrm{P}_{\mathrm{y}}$ superstructure with $k_{\text {app }}=57 \times 10^{-2} \min ^{-1}$ [27]; $\mathrm{Lu}$ and his coworkers prepared $\mathrm{Ni} @ \mathrm{Ni}_{\mathrm{x}} \mathrm{P}_{\mathrm{y}}$ core-shell microstructures with $k_{a p p}=38 \times 10^{-2} \mathrm{~min}^{-1}$ [28]; Huang et al. fabricated porous $\mathrm{Co}_{2} \mathrm{P}$ for hydrogenation of 4-NP with the $k_{a p p}=0.09 \times 10^{-2} \mathrm{~min}^{-1}$ [3]; Lu et al. synthesized CoP nanoflakes with $k_{a p p}=34 \times 10^{-2} \mathrm{~min}^{-1}$ [29].

Since both $\mathrm{CoP}$ and $\mathrm{Ni}_{2} \mathrm{P}$, with high hydrogenation efficiency for 4-NP, can the two materials be combined together to enhance the catalytic efficiency in the premise that structure and morphology are not broken? Perhaps the synergistic effect between Ni and Co will lead to better catalytic efficiency. To our knowledge, there has no report on the catalytic performance of composite of $\mathrm{Ni}_{\mathrm{x}} \mathrm{Co}_{\mathrm{y}} \mathrm{P}$.

In this work, we firstly report the fabrication, structure, and performance of porous $\mathrm{Ni}_{x} \mathrm{Co}_{\mathrm{y}} \mathrm{P}$ composites, and discuss the synergistic effects of $\mathrm{Ni}$ and $\mathrm{Co}$ in a hydrogenation process. The results demonstrate that the $\mathrm{NiCoP}$ composite nanomaterials have excellent catalytic efficiency and promising application as catalyst for 4-NP reduction.

\section{Experimental}

\subsection{Catalyst Synthesis}

The porous phosphide catalysts were prepared in three steps as the displayed in Figure 1. Firstly, $\mathrm{NiCl}_{2} \cdot 6 \mathrm{H}_{2} \mathrm{O}(0 \mathrm{mmol}$, or $0.66 \mathrm{mmol}$, or $1 \mathrm{mmol}$, or $1.33 \mathrm{mmol}), \mathrm{CoCl}_{2} \cdot 6 \mathrm{H}_{2} \mathrm{O}(2 \mathrm{mmol}$, or $1.33 \mathrm{mmol}$, or $1 \mathrm{mmol}$, or $0.66 \mathrm{mmol}$ ) and urea $(0.2 \mathrm{~g})$ were dissolved in a solution containing $20 \mathrm{~mL}$ deionized (DI) water and $20 \mathrm{~mL}$ glycol to form a transparent solution. Then, the solution was transferred into a 50-mL Teflon-lined autoclave and then kept in an oven at $140{ }^{\circ} \mathrm{C}$ for $10 \mathrm{~h}$. The resulting precipitate precursors were gathered and cleaned with ethanol and DI water for several times. Secondly, the precursors were calcinated at $400{ }^{\circ} \mathrm{C}$ for $2 \mathrm{~h}$ in air, and black cobalt nickel oxides were obtained. Thirdly, the superfluous $\mathrm{NaH}_{2} \mathrm{PO}_{2}$ with the cobalt nickel oxides were mixed well and then heated to $250{ }^{\circ} \mathrm{C}$ for $2 \mathrm{~h}$ in Ar atmosphere. The final products were washed several times with DI water and ethanol.

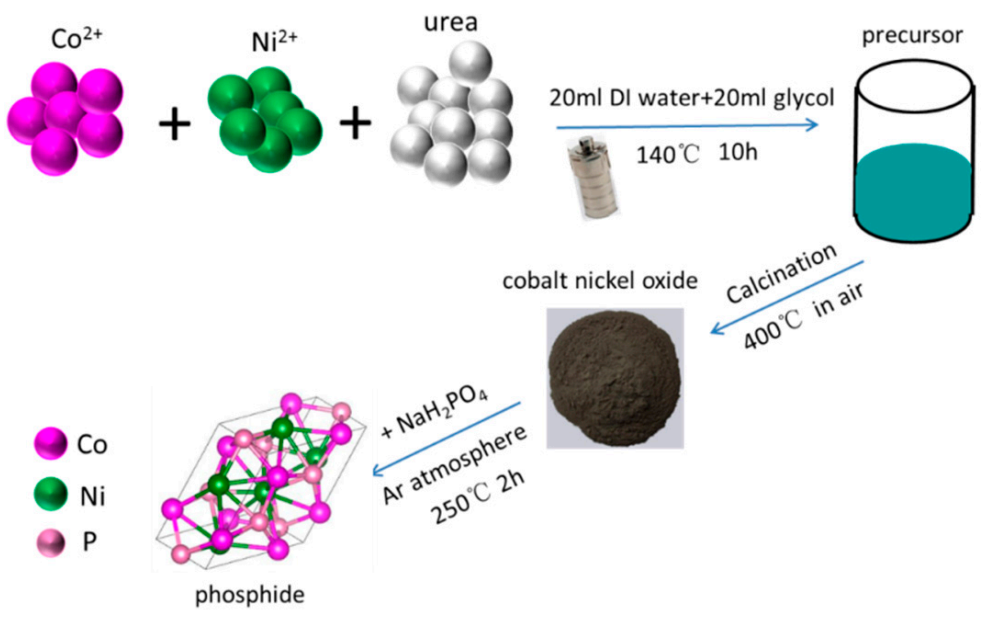

Figure 1. Schematic depiction of the synthesis process. 


\subsection{Characterization}

A powder X-ray diffraction (XRD) was conducted to determine the phase of the as-synthesized composites, with $\mathrm{Cu} \mathrm{K} \alpha$ radiation operated at $40 \mathrm{kV}$ and $30 \mathrm{~mA}$. The morphologies and microstructures of the composites were characterized by employing field emission scanning electron microscope (FE-SEM, Hitachi S-4800) and Energy dispersive X-ray Spectroscopy (EDX). X-ray photoelectron spectroscopy (XPS) experiments were carried out by a Kratos XSAM 800 system with an Al K $\alpha$ X-ray photoelectron spectrometer.

\subsection{Catalyze Measurements}

The measurements for the catalytic hydrogenation of 4-NP by catalyst were conducted by UV-Vis spectroscopy in a quartz cuvette on a UV-visible spectrophotometer (TU-1901). A total amount of $3 \mathrm{~mL}$ of 4-NP, which was prepared by dissolving $5 \mathrm{~mL} 4-\mathrm{NP}(1 \mathrm{mM})$ and $1 \mathrm{mmol} \mathrm{NaBH}_{4}$ reagent into $45 \mathrm{~mL}$ DI water was moved into a quartz cuvette. After that, different phosphide catalyst suspension was injected into the cuvette to trigger the reaction, and the UV-Vis absorbance spectra were monitored to describe the process of reaction. The reduction of 4-NP was conducted in the existence of excess freshly prepared $\mathrm{NaBH}_{4}$, and the reduction process can be described two steps as shown in Figure 2 . Firstly, 4-NP interacts rapidly with the hydroxyl ion induced by hydrolysis of sodium borohydride. As a result, 4-NP is converted to 4-nitrophenolate ions (4-NPI). After that, the 4-NPI is reduced by $\mathrm{NaBH}_{4}$ and 4-AP comes is formed. All of the measurements were conducted at room temperature.

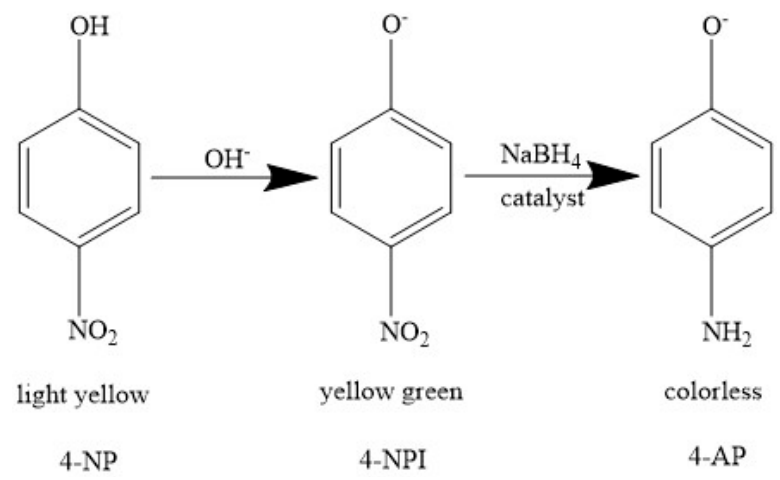

Figure 2. Conversion from 4-NP to 4-AP.

\section{Results and Discussion}

\subsection{Characterization of Samples}

Figure 3 shows the XRD patterns of the four catalysts. When the Ni/Co molar ratio is $0,0.5,1$, and 2, the XRD patterns are typical phases of $\mathrm{CoP}, \mathrm{NiCoP} / \mathrm{CoP}, \mathrm{NiCoP}$, and $\mathrm{NiCoP} / \mathrm{Ni}_{2} \mathrm{P}$. Besides, the results show that $\mathrm{NiCoP}$ and $\mathrm{Ni}_{2} \mathrm{P}$ have same hexagonal structure while $\mathrm{CoP}$ is oethorhombic structure. For the CoP samples, the diffraction peaks at $31.58^{\circ}, 36.31^{\circ}, 46.16^{\circ}, 48.08^{\circ}, 52.13^{\circ}$ and $56.09^{\circ}$ can be assigned to the (011), (111), (112), (211), (103) and (020) planes of CoP (JCPDS no.65-2593), respectively. For the NiCoP samples, the diffraction peaks at $40.92^{\circ}, 44.88^{\circ}, 47.61^{\circ}, 54.45^{\circ}$ and $75.43^{\circ}$ can be assigned to the (111), (201), (210), (300) and (212) planes of NiCoP (JCPDS no. 71-2336), respectively. Because the XRD patterns of $\mathrm{Ni}_{2} \mathrm{P}$ and $\mathrm{NiCoP}$ are very similar, it is difficult to distinguish the two kinds of phosphides. However, a detailed comparison of the XRD patterns of $\mathrm{Ni}_{2} \mathrm{P}$ and $\mathrm{NiCoP}$ reveals that there is a slight shift towards higher $2 \theta$ position due to introduction of $\mathrm{Co}$ and indicative of the formation of NiCoP ternary phosphide [30]. Meanwhile, the diffraction peaks at $40.92^{\circ}$ in the XRD pattern of NiCoP/CoP sample could be assigned to the (111) plane of NiCoP (JCPDS no. 71-2336) and peaks at $31.58^{\circ}, 36.43^{\circ}, 48.10^{\circ}$ and $52.16^{\circ}$ could be assigned to the (011), (111), (211) and (020) planes of CoP (JCPDS no.65-2593), respectively. When the Ni/Co molar ratio is 2 , the XRD pattern shows the 
products were the mixture of $\mathrm{NiCoP}$ and $\mathrm{Ni}_{2} \mathrm{P}$. This indicates that the $\mathrm{Ni} / \mathrm{Co}$ molar ratio plays a very important role in the phase and crystal structure of products.

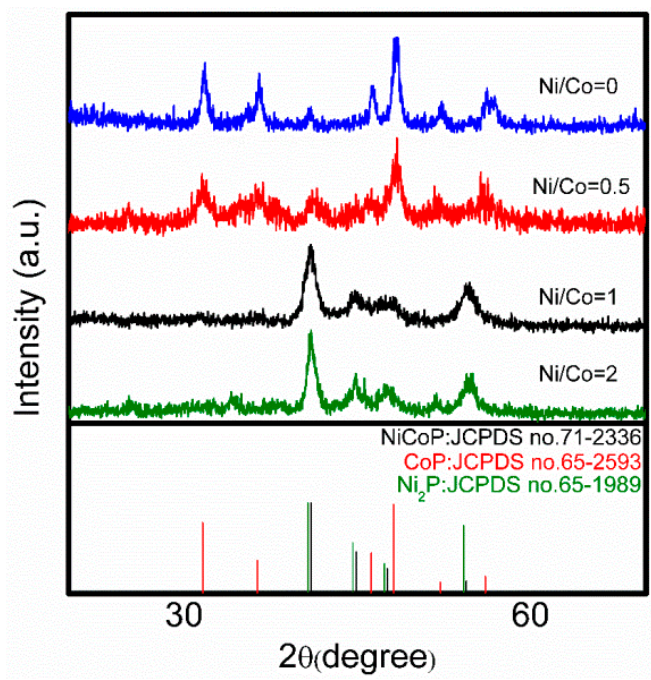

Figure 3. XRD patterns of the $\mathrm{Ni}_{x} \mathrm{Co}_{\mathrm{y}} \mathrm{P}$ which prepared with different $\mathrm{Ni} / \mathrm{Co}$ molar ratios.

To further investigate the effect of the molar ratio of Ni/Co on the products, XPS measurement of the phosphides was carried out. Figure $4 a-c$ shows XPS spectra of Co $(2 p), N i(2 p)$ and P $(2 p)$ for the $\mathrm{CoP}, \mathrm{NiCoP} / \mathrm{CoP}, \mathrm{NiCoP}$ and $\mathrm{NiCoP} / \mathrm{Ni}_{2} \mathrm{P}$, respectively. The $\mathrm{Ni} 2 \mathrm{p}_{3 / 2}$ peak can be fitted with three peaks at 853.1, 856.35 eV and $861.55 \mathrm{eV}$ that correspond to $\mathrm{Ni}$ in $\mathrm{Ni}_{2} \mathrm{P}$ or $\mathrm{NiCoP}, \mathrm{Ni}$ oxides species and the satellite peak, respectively [8,17,31-33]. For the CoP sample, the peaks of Co $2 \mathrm{p}_{3 / 2}$ located at 778.2 and $782.0 \mathrm{eV}$ correspond to the Co-P bond and Co oxides, respectively [29,34,35]. For the other three samples, the peaks located at $778.50 \mathrm{eV}$ for Co are ascribed to the Co-P bonds in NiCoP. The blue shift $(0.22 \mathrm{eV})$ of $\mathrm{Co} 2 \mathrm{p}_{3 / 2}$ peak shows unambiguously that Co has a strong coupling effect and change the surface electronic landscape [36,37]. Besides, the binding energies of $\mathrm{P} 2 \mathrm{p}$ region show a presence of two peaks at 129.1 and $133.2 \mathrm{eV}$ belonged to metal phosphide bonds and $\mathrm{P}$ oxides, indicating that $\mathrm{P}$ is not involved in the process of adjusting multi-coupling synergetic effects in all samples [14,34,38]. The observation of oxide species of $\mathrm{Co}, \mathrm{Ni}$ and $\mathrm{P}$ in the XPS results is due to the spontaneous oxidation of samples exposed to air [39]. All these results demonstrate that the products were CoP, NiCoP/CoP, $\mathrm{NiCoP}$ and $\mathrm{NiCoP} / \mathrm{Ni}_{2} \mathrm{P}$ when the $\mathrm{Ni} / \mathrm{Co}$ ratios were $0,0.5,1$, and 2 , respectively.

Recent studies have shown that both $\mathrm{NiCoP}$ and $\mathrm{Ni}_{2} \mathrm{P}$ consist of interlinked trigonal prisms centered by $\mathrm{P}$ atoms [40]. This structure of NiCoP can be described as $\mathrm{P}$ atoms-sharing stacks. In this work, it is obvious that the $\mathrm{CoP}$ can be produced when the $\mathrm{Ni} / \mathrm{Co}=0$. When the molar ratio of $\mathrm{Ni}$ equals to or higher than $\mathrm{Co}, \mathrm{NiCoP}$ phase appears in the XRD patterns. Besides, the $\mathrm{NiCoP}$ and $\mathrm{Ni}_{2} \mathrm{P}$ show the same hexagonal structure in this work. It is reasonable to make the assumption that Co atoms partially substitute $\mathrm{Ni}$ atoms of $\mathrm{Ni}_{2} \mathrm{P}$ to form $\mathrm{NiCoP}$ phase, which is similar with the $\mathrm{NiMoP}$ system reported in the literature [41]. However, when the molar ratio of $\mathrm{Ni}$ is lower than that of $\mathrm{Co}$, a mixture composition of $\mathrm{NiCoP} / \mathrm{CoP}$ was produced. This result shows that not all of Ni atoms in the $\mathrm{Ni}_{2} \mathrm{P}$ phase can be replaced by $\mathrm{Co}$ atoms. Therefore, the $\mathrm{Ni} / \mathrm{Co}$ ratio has a significant influence on the formation of products.

The effect of a different $\mathrm{Ni} / \mathrm{Co}$ molar ratio on the microstructure of products were explored by SEM. Figure 5 shows the SEM images of the precursors and corresponding oxides prepared with different $\mathrm{Ni}$ /Co molar ratios. The images indicate that the sample consists of nanorods when the molar ratio of $\mathrm{Ni}$ is lower than that of $\mathrm{Co}$ and consists of the mixture of nanoflakes and nanorods when the molar ratio of $\mathrm{Ni}$ equals to or higher than $\mathrm{Co}$. This implies that it tends to form nanoflakes at larger $\mathrm{Ni} /$ Co molar ratio. 

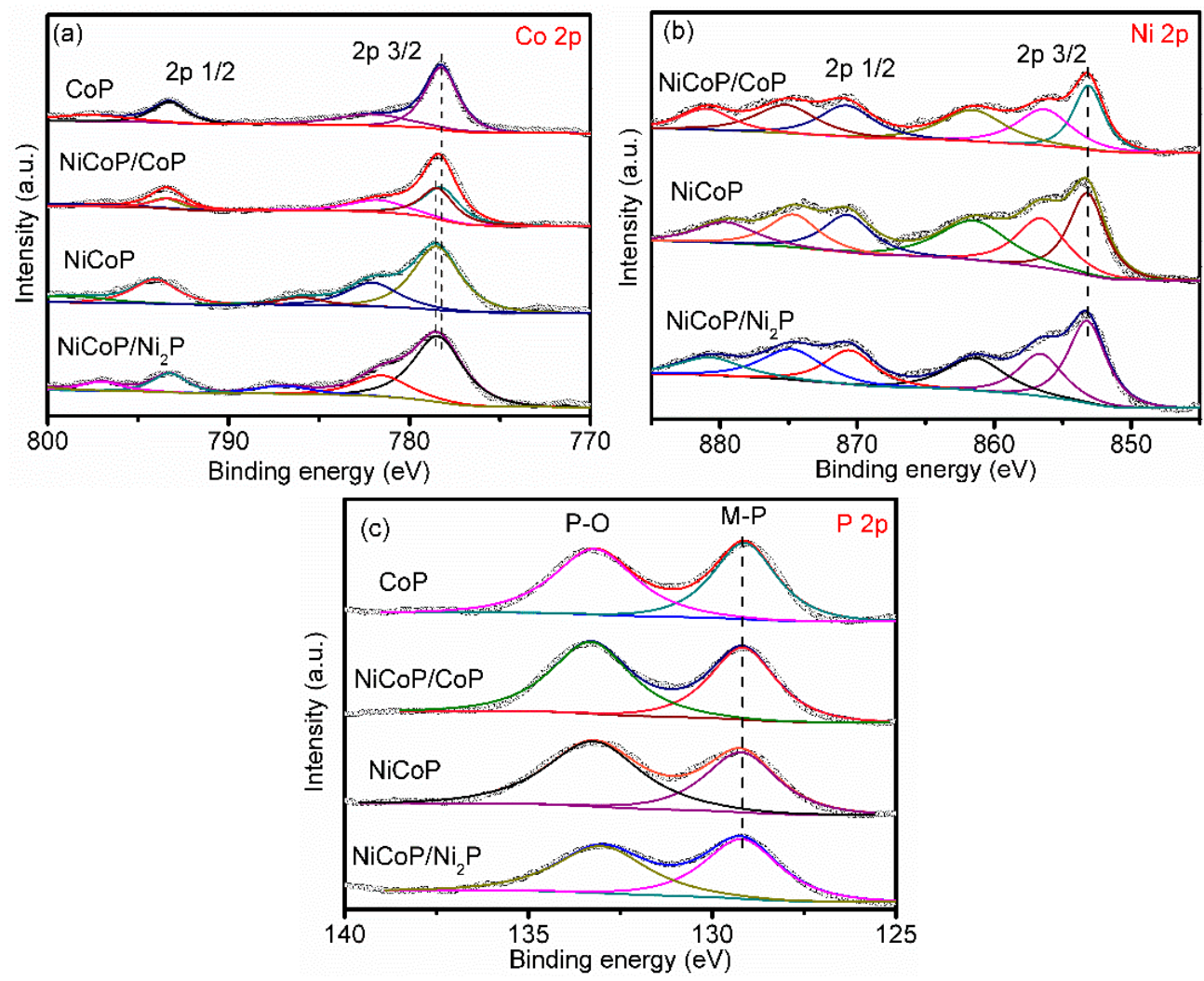

Figure 4. The high-resolution Co 2p (a), Ni 2p (b) and P 2p (c) XPS spectra of CoP, NiCoP/CoP, NiCoP and $\mathrm{NiCoP}$, respectively.
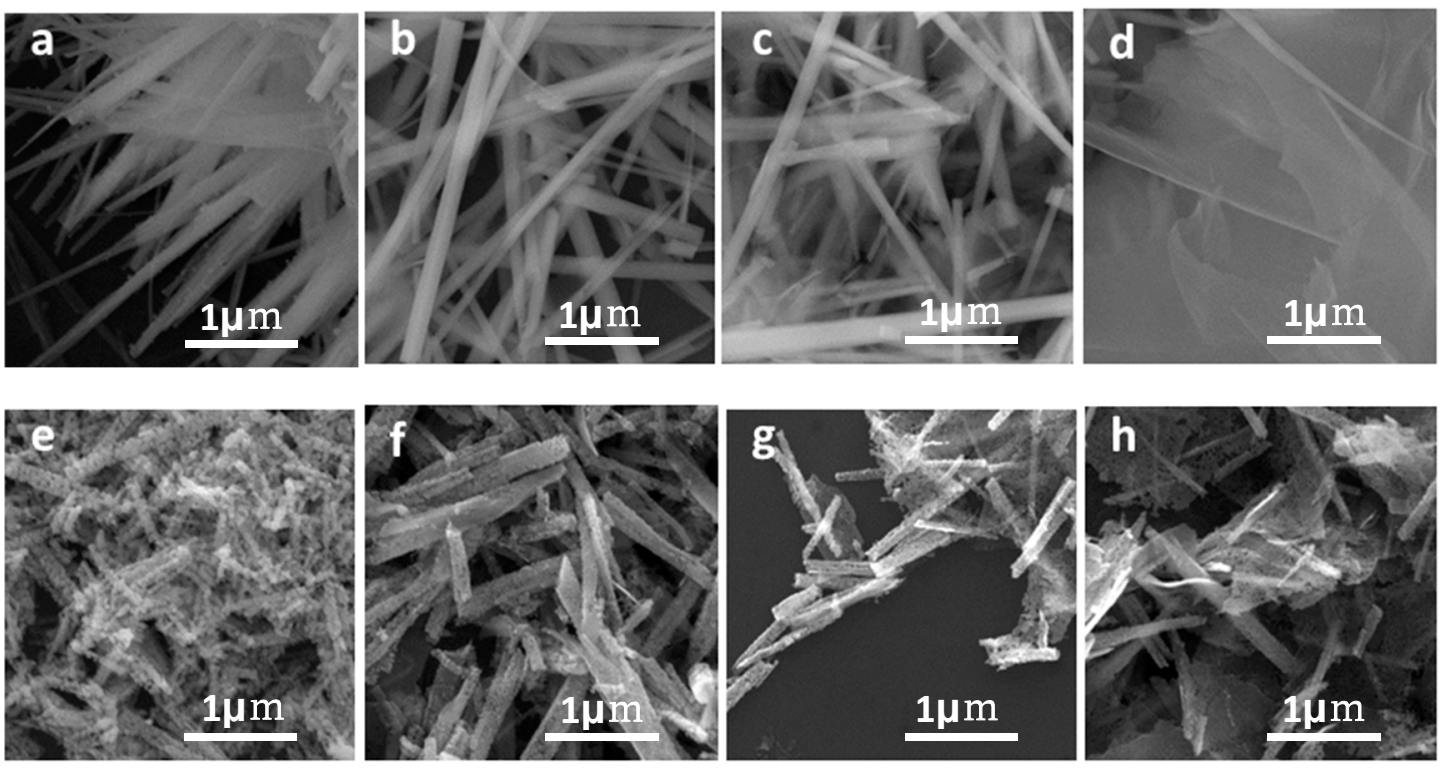

Figure 5. SEM images of (a-d) different precursors prepared by different $\mathrm{Ni} / \mathrm{Co}$ molar ratios, and (e-h) the corresponding oxides.

Figure 6 demonstrates that the phosphide samples with different $\mathrm{Ni}$ /Co molar ratios are composed of porous nanostructures. The formation of this specific morphology and structure is attributed to the gas release during the calcination. Furthermore, the EDX-Mapping images indicate the homogeneous distribution of $\mathrm{P}, \mathrm{Co}$ and $\mathrm{Ni}$ elements on the $\mathrm{Ni}_{\mathrm{x}} \mathrm{Co}_{\mathrm{y}} \mathrm{P}$, as shown in Figure 7. The uniform distribution of each element reveals the successful synthesis of $\mathrm{Ni}_{x} \mathrm{Co}_{\mathrm{y}} \mathrm{P}$ nanostructure. 

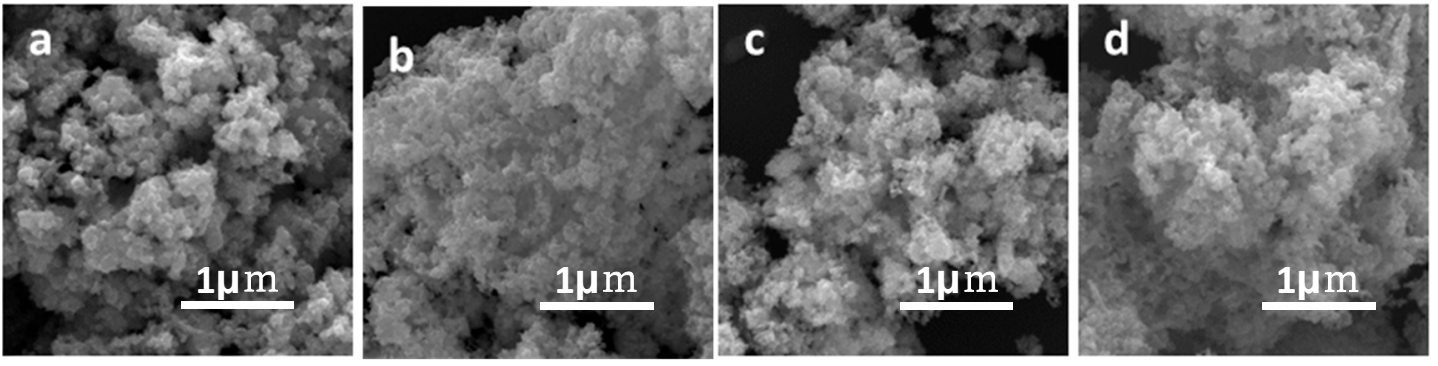

Figure 6. SEM images of (a) CoP, (b) NiCoP/CoP, (c) NiCoP and (d) $\mathrm{NiCoP} / \mathrm{Ni}_{2} \mathrm{P}$.
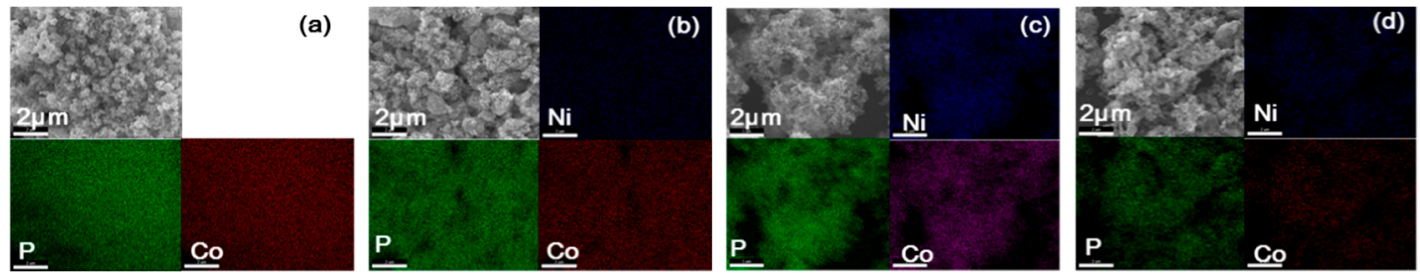

Figure 7. SEM images and corresponding to SEM-EDS mapping images reflects $\mathrm{P}, \mathrm{Co}$ and $\mathrm{Ni}$ atom distributions for the (a) $\mathrm{CoP},(\mathbf{b}) \mathrm{NiCoP} / \mathrm{CoP},(\mathbf{c}) \mathrm{NiCoP}$ and (d) NiCoP/Ni $2 \mathrm{P}$.

\subsection{Catalytic Activity}

Previous reports have testified that the reduction reaction of 4-NP is difficult without catalysts. Nevertheless, the 4-NP can be rapidly reduced when catalysts involve in the reaction. A UV-Vis spectroscopy is employed to monitor the reduction process in this work. As shown in Figure 8a, the maximum absorption at $400 \mathrm{~nm}$ in the UV-Vis spectra reduces rapidly because of the reduction of 4-NP. At the same time, another peak emerges at $300 \mathrm{~nm}$ owing to the formation of 4-AP [42]. A few minutes later, the absorption peak of 4-NP disappears and color of the solution fades from dark yellow to transparent. Therefore, it is reasonable to monitor the intensity of the absorption peak at $400 \mathrm{~nm}$ to investigate the kinetic process of the reduction reaction. For comparison, the catalytic activity of $\mathrm{CoP}, \mathrm{NiCoP} / \mathrm{CoP}, \mathrm{NiCoP}$ and $\mathrm{NiCoP} / \mathrm{Ni}_{2} \mathrm{P}$ were tested under the same condition, and the amount of each catalyst is $0.06 \mathrm{mg}$. In Figure $8 \mathrm{a}$, the decrease of peak at $300 \mathrm{~nm}$ is owing to the precipitation of catalysts in quartz cuvette during optical absorption measurements. These results are consistent with literatures $[8,43]$. Figure $8 \mathrm{~b}$ displays the conversion-time dependent curves of 4-NP to 4-AP for various catalysts. $93 \%$ conversion of $4-\mathrm{NP}$ is selected for comparison and the conversion time was $9 \mathrm{~min}, 6 \mathrm{~min}, 3 \mathrm{~min}$ and $4 \mathrm{~min}$ for the different catalyst, respectively. The catalytic activity of the four catalysts follows the sequence of $\mathrm{NiCoP} / \mathrm{Ni}_{2} \mathrm{P}>\mathrm{NiCoP}>\mathrm{NiCoP} / \mathrm{CoP}>\mathrm{CoP}$. The results demonstrate that the enhancement of catalytic activity of NiCoP sample. There is an induction period in catalytic reaction and it is an initial slow stage of a chemical reaction. After the induction period, the reaction accelerates [44]. As shown in Figure 8b, the induction period was $2 \mathrm{~min}, 1 \mathrm{~min}$ and $1 \mathrm{~min}$ for CoP, $\mathrm{NiCoP} / \mathrm{CoP}$ and $\mathrm{NiCoP} / \mathrm{Ni}_{2} \mathrm{P}$, respectively. However, the induction period vanishes and a faster reaction rate was observed for $\mathrm{NiCoP}$.

The hydrogenation process of 4-NP follows the pseudo-first order kinetics, which can be described with a kinetic equation:

$$
\ln \left(C_{t} / C_{0}\right)=\ln \left(A_{t} / A_{0}\right)=-k_{\text {app }} t,
$$

where $A_{t}$ is the absorbance at $400 \mathrm{~nm}$ at time $t ; A_{0}$ is the initial absorbance of the reactants; $t$ is the reaction time; $k_{a p p}$ is the apparent rate constant $\left(\mathrm{s}^{-1}\right)$, respectively. Thus, the apparent rate constant $\left(k_{\text {app }}\right)$, which is determined by the spectrophotometric data, can give information on the reaction rate [45]. Figure 9a illustrates the relationship of $\ln \left(A_{t} / A_{0}\right)$ versus reaction time plots in presence of $0.06 \mathrm{mg}$ catalysts. The observed $k_{a p p}$ for $\mathrm{NiCoP}, \mathrm{NiCoP} / \mathrm{Ni}_{2} \mathrm{P}, \mathrm{NiCoP} / \mathrm{CoP}$ and $\mathrm{CoP}$ is $677.4 \times 10^{-2} \mathrm{~min}^{-1}, 312.6 \times 10^{-2} \mathrm{~min}^{-1}, 259.8 \times 10^{-2} \mathrm{~min}^{-1}$ and $163.8 \times 10^{-2} \mathrm{~min}^{-1}$, respectively. 
In addition, the effect of different catalyst dosages for 4-NP reduction is also investigated. Therefore, the parametric $k$ is measured, which is related to the catalyst amount, and is defined as [46]:

$$
k=\frac{k_{a p p}}{m / V^{\prime}}
$$

where $m$ is the mass of catalysts, and $V$ is the volume of the catalytic system. In Table 1 , the $k$ values were calculated. The observed $k$ for $\mathrm{NiCoP}, \mathrm{NiCoP} / \mathrm{Ni}_{2} \mathrm{P} \mathrm{NiCoP} / \mathrm{CoP}$ and $\mathrm{CoP}$ is $338.7\left(\mathrm{Lg}^{-1} \mathrm{~min}^{-1}\right)$, $156.3\left(\mathrm{Lg}^{-1} \mathrm{~min}^{-1}\right), 129.9\left(\mathrm{Lg}^{-1} \mathrm{~min}^{-1}\right)$ and $81.9\left(\mathrm{Lg}^{-1} \mathrm{~min}^{-1}\right)$, respectively.
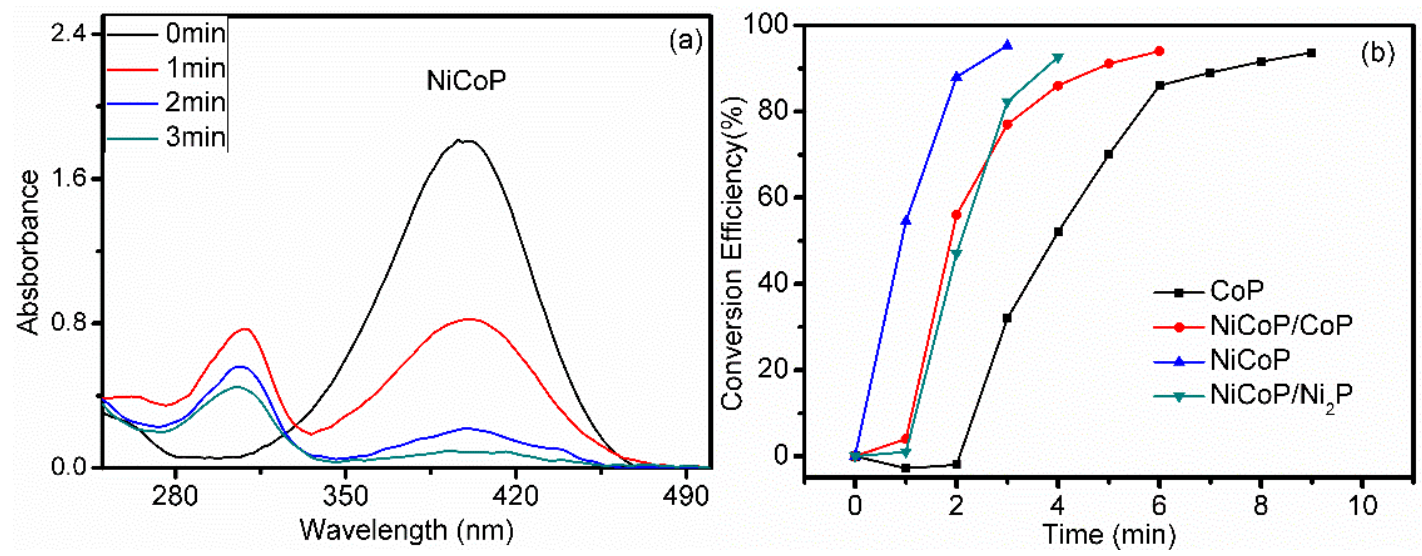

Figure 8. (a) UV-Vis spectra of 4-NP catalyzed in presence of NiCoP at different time. (b) The relationships between reduction efficiency of 4-NP and reaction time in the present of $\mathrm{CoP}, \mathrm{NiCoP} / \mathrm{CoP}$, $\mathrm{NiCoP}$ and $\mathrm{NiCoP} / \mathrm{Ni}_{2} \mathrm{P}$, respectively.

Figure $9 \mathrm{~b}$ shows that the catalytic efficiency varies with the $\mathrm{Ni} / \mathrm{Co}$ molar ratio and indicates that $\mathrm{NiCoP}$ is a superior catalyst for reduction the 4-NP. Furthermore, both $\mathrm{NiCoP} / \mathrm{CoP}$ and $\mathrm{NiCoP} / \mathrm{Ni}{ }_{2} \mathrm{P}$ have lower efficiency than NiCoP, which indicates the higher hydrogenation activity of the ternary phosphide $(\mathrm{NiCoP})$ than the binary phosphide (CoP or $\mathrm{Ni}_{2} \mathrm{P}$ ). Compared with other reported phosphide catalysts as shown in Table 1, NiCoP is with better catalytic efficiency. In addition, as shown in Table 1, the activity of $\mathrm{NiCoP}$ is even better than some noble metal catalysts and rGO catalysts, which further exhibits the superior catalytic ability of the ternary phosphides for 4-NP reduction. $\mathrm{NiCoP}$ was fabricated by the process of $\mathrm{Co}$ atoms partially substituting $\mathrm{Ni}$ atoms of $\mathrm{Ni}_{2} \mathrm{P}$, so the higher catalytic activity of $\mathrm{NiCoP}$ than $\mathrm{Ni}_{2} \mathrm{P}$ can be ascribed to the increased Co sites in the $\mathrm{NiCoP}$ sample [21]. $\mathrm{NiCoP}$ has $\mathrm{Ni}^{\alpha+}(0 \leq \alpha \leq 1)$ and $\mathrm{Co}^{\beta+}(0 \leq \beta \leq 1)$ sites, indicating that $\mathrm{Co}$ has $\mathrm{Co}^{2+}, \mathrm{Co}^{+}$ and $\mathrm{Co}^{0}$ states [22]. As proved by Lining Ding, $\beta$ will be very close to zero when the number of $\mathrm{Ni}$ atoms is more than that of Co atoms [21]. Thus, the increase of $\mathrm{Ni}$ atoms leads to the reduction of catalytic performance and the interaction of electron was modified by the existence of neighboring Ni. So its superior catalytic ability of NiCoP can be attributed to the synergy between $\mathrm{Ni}$ and Co and the increased electron density of Co sites. The mechanism of 4-NP reduction can be described as follows: Firstly, $\mathrm{P}$ acts as the proton-acceptor and combines with $\mathrm{H}$ which generates from the dissociation of $\mathrm{B}-\mathrm{H}$ and $\mathrm{Co}$ combines with $\mathrm{BH}_{3}^{-}$. Secondly, $\mathrm{e}^{-}$captured from $\mathrm{BH}_{3}^{-}$transmits to $\mathrm{P}$ under the help of the captured $\mathrm{e}^{-}$, and the $\mathrm{P}$ receives a $\mathrm{H}$ from the $\mathrm{O}-\mathrm{H}$. Thirdly, $\mathrm{H}$ is delivered from $\mathrm{P}$ to $\mathrm{Co}$ at the same time, the $\mathrm{H}$ at the Co surface reacts with 4-NP to yield 4-AP. Finally, the 4-AP is desorbed from the surface of NiCoP [51].

In addition, the effect of different catalyst dosage on the reaction has also been observed in Figure $9 \mathrm{c}$. The results show that the $k_{a p p}$ increases linearly with the increasing amount of the catalyst, due to the increase of reaction sites. 

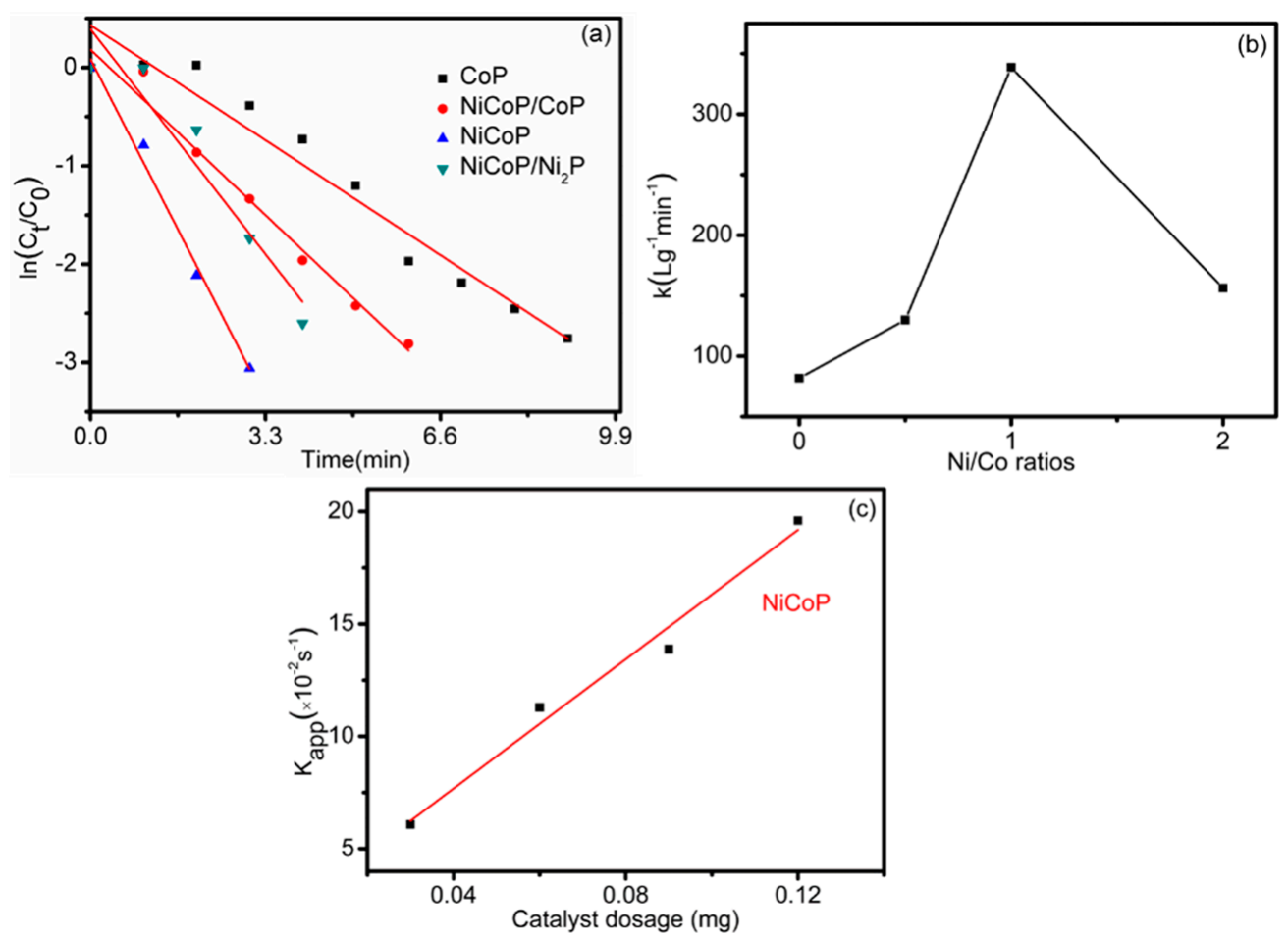

Figure 9. (a) The plots of $\ln \left(\mathrm{C}_{t} / \mathrm{C}_{0}\right)$ versus the reaction time for the reduction of 4-NP catalyzed by CoP, $\mathrm{NiCoP} / \mathrm{CoP}, \mathrm{NiCoP}$, and NiCoP. (b) The catalytic efficiency varies with the Ni/Co molar ratio. (c) Effect of catalyst dosage on reduction of 4-NP catalyzed by NiCoP catalysts in the presence of $\mathrm{NaBH}_{4}$.

Table 1. Comparison of the catalytic $k_{a p p}$ and $k$ in this work with other phosphide catalysts previously reported for the reduction of 4-NP.

\begin{tabular}{|c|c|c|c|c|}
\hline Catalyst & Ni/Co Ratios & $\begin{array}{c}k_{a p p} \\
\left(\times 10^{-2} \min ^{-1}\right)\end{array}$ & $\begin{array}{c}\mathrm{k} \\
\left(\mathrm{Lg}^{-1} \mathrm{~min}^{-1}\right)\end{array}$ & \\
\hline $\mathrm{CoP}$ & 0 & 163.8 & 81.9 & This work \\
\hline $\mathrm{NiCoP} / \mathrm{CoP}$ & 0.5 & 259.8 & 129.9 & This work \\
\hline $\mathrm{NiCoP}$ & 1 & 677.4 & 338.7 & This work \\
\hline $\mathrm{NiCoP} / \mathrm{Ni}_{2} \mathrm{P}$ & 2 & 312.6 & 156.3 & This work \\
\hline $\mathrm{Co}_{2} \mathrm{P}$ & - & 0.09 & 0.45 & [3] \\
\hline $\mathrm{CoP}$ & - & 34 & 34 & [29] \\
\hline $\mathrm{Ni}_{2} \mathrm{P} / \mathrm{Ni}_{12} \mathrm{P}_{5}$ & - & 50.04 & 1.0 & [8] \\
\hline $\mathrm{Ni} @ \mathrm{Ni}_{\mathrm{x}} \mathrm{P}_{\mathrm{y}}$ & - & 38 & 1.58 & [28] \\
\hline $\mathrm{Ni}_{\mathrm{x}} \mathrm{P}_{\mathrm{y}}$ & - & 57 & 8.54 & [27] \\
\hline $\mathrm{FeCo}$ & - & 49.68 & 24.84 & [47] \\
\hline $\mathrm{Co}_{0.85} \mathrm{Se}-\mathrm{Fe}_{3} \mathrm{O}_{4}$ & - & - & 1.18 & [11] \\
\hline AuPd & - & - & 106.56 & [48] \\
\hline AgPdNCs/rGO & - & 3.65 & 98.55 & [49] \\
\hline AgNPs/SiNSs & - & 481.14 & 24.06 & [50] \\
\hline Ni/rGO@Au & - & 52.38 & 14.90 & [13] \\
\hline
\end{tabular}

\section{Conclusions}

A series of phosphide catalysts, $\mathrm{CoP}, \mathrm{NiCoP} / \mathrm{CoP}, \mathrm{NiCoP}$ and $\mathrm{NiCoP}$ have been fabricated. The Ni/Co ratio has important influence on the formation of phosphide and the activity for 4-NP decomposition. Among the phosphides, NiCoP catalyst showed the best performance of 4-NP decomposition due to the synergy between $\mathrm{Ni}$ and $\mathrm{Co}$ atoms. Compared with $\mathrm{Ni}^{\alpha+}, \mathrm{Co}^{\beta+}$ exhibits a higher efficiency of reduction 4-NP because of the electronic interactions among $\mathrm{Co}, \mathrm{P}$ and $\mathrm{Ni}$ atoms. So the increased electron density of Co sites explains the enhanced activity of the NiCoP catalyst. 
Author Contributions: Conceptualization, L.S.; methodology, X.X.; software, J.W.; validation, L.S., C.C. and D.A.; formal analysis, L.S. and X.X.; investigation, L.S.; resources, X.X.; data curation, L.S.; writing-original draft preparation, L.S.; writing-review and editing, X.X.; visualization, J.W.; supervision, X.X., C.T. and J.L.; project administration, X.Z.; funding acquisition, X.Z.

Funding: This research was funded by the NSAF Joint Foundation of China, grant number U1630126.

Conflicts of Interest: The authors declare no conflict of interest.

\section{References}

1. Tian, C.X.; Xiang, X.; Wu, J.W.; Li, B.; Cai, C.; Khan, B.; Chen, H.; Yuan, Y.G.; Zu, X.T. Facile Synthesis of MoS2/CuS Nanosheet Composites as an Efficient and Ultrafast Adsorbent for Water-Soluble Dyes. J. Chem. Eng. Data 2018, 63, 3966-3974. [CrossRef]

2. Li, X.; Wu, K.; Ye, Y.; Wei, X. Gas-assisted growth of boron-doped nickel nanotube arrays: Rapid synthesis, growth mechanisms, tunable magnetic properties, and super-efficient reduction of 4-nitrophenol. Nanoscale 2013, 5, 3648-3653. [CrossRef] [PubMed]

3. Huang, $\mathrm{X}$.; $\mathrm{Wu}, \mathrm{D}$; Cheng, D. Porous $\mathrm{CO}_{2} \mathrm{P}$ nanowires as high efficient bifunctional catalysts for 4-nitrophenol reduction and sodium borohydride hydrolysis. J. Colloid Interface Sci. 2017, 507, 429-436. [CrossRef]

4. Politano, A.; Gianluca, D.P.; Fontananova, E.; Sanna, V.; Cupolillo, A.; Curcio, E. Overcoming temperature polarization in membrane distillation by thermoplasmonic effects activated by Ag nanofillers in polymeric membranes. Desalination 2019, 451, 192-199. [CrossRef]

5. Politano, A.; Argurio, P.; Di Profio, G.; Sanna, V.; Cupolillo, A.; Chakraborty, S.; Arafat, H.A.; Curcio, E. Photothermal Membrane Distillation for Seawater Desalination. Adv. Mater. 2017, 29, 1603504. [CrossRef]

6. Gugliuzza, A.; Politano, A.; Drioli, E. The advent of graphene and other two-dimensional materials in membrane science and technology. Curr. Opin. Chem. Eng. 2017, 16, 78-85. [CrossRef]

7. Politano, A.; Cupolillo, A.; Di Profio, G.; Arafat, H.A.; Chiarello, G.; Curcio, E. When plasmonics meets membrane technology. J. Phys.-Condens. Matter 2016, 28, 363003. [CrossRef]

8. Tian, F.Y.; Hou, D.; Zhang, W.M.; Qiao, X.Q.; Li, D.S. Synthesis of a $\mathrm{Ni}_{2} \mathrm{P} / \mathrm{Ni}_{12} \mathrm{P}_{5}$ bi-phase nanocomposite for the efficient catalytic reduction of 4-nitrophenol based on the unique n-n heterojunction effects. Dalton Trans. 2017, 46, 14107-14113. [CrossRef]

9. Seo, Y.S.; Ahn, E.-Y.; Park, J.; Kim, T.Y.; Hong, J.E.; Kim, K.; Park, Y.; Park, Y. Catalytic reduction of 4-nitrophenol with gold nanoparticles synthesized by caffeic acid. Nanoscale Res. Lett. 2017, 12, 7. [CrossRef]

10. Nitti, A.; Signorile, M.; Boiocchi, M.; Bianchi, G.; Po, R.; Pasini, D. Conjugated Thiophene-Fused Isatin Dyes through Intramolecular Direct Arylation. J. Org. Chem. 2016, 81, 11035-11042. [CrossRef]

11. Song, J.M.; Zhang, S.S.; Yu, S.H. Multifunctional $\mathrm{Co}_{0.85} \mathrm{Se}-\mathrm{Fe}_{3} \mathrm{O}_{4}$ nanocomposites: Controlled synthesis and their enhanced performances for efficient hydrogenation of p-nitrophenol and adsorbents. Small 2014, 10, 717-724. [CrossRef] [PubMed]

12. Jhimli, P.G.; Bhardwaj, Y.K.; Lalit, V. Chemically clean synthesis and characterization of graphene oxide-poly(acrylic acid-sodium styrene sulfonate) composite thermostable elastic gel encapsulating copper nanoparticles for efficient catalytic reduction of 4-nitrophenol. J. Appl. Polym. Sci. 2017, 135, 46200.

13. Cao, M.; Feng, L.; Yang, P.; Wang, H.; Liang, X.; Chen, X. Fabrication of reduced graphene oxide decorated with gold and nickel for the catalytic reduction of 4-nitrophenol. J. Mater. Sci. 2017, 53, 4874-4883. [CrossRef]

14. Liu, Y.; Zhu, Y.; Shen, J.; Huang, J.; Yang, X.; Li, C. CoP nanoparticles anchored on N,P-dual-doped graphene-like carbon as a catalyst for water splitting in non-acidic media. Nanoscale 2018, 10, 2603-2612. [CrossRef] [PubMed]

15. Lu, X.; Zhao, C. Electrodeposition of hierarchically structured three-dimensional nickel-iron electrodes for efficient oxygen evolution at high current densities. Nat. Commun. 2015, 6, 6616. [CrossRef] [PubMed]

16. Han, J.; Jia, H.; Yang, Z.; Fan, Q.; Zhang, F. Confined hexahedral nickel nanoparticle catalyst for catalytic hydrogenation reaction. J. Mater. Sci. 2017, 53, 4884-4896. [CrossRef]

17. Xiao, X.; Huang, D.; Fu, Y.; Wen, M.; Jiang, X.; Lv, X.; Li, M.; Gao, L.; Liu, S.; Wang, M.; et al. Engineering $\mathrm{NiS} / \mathrm{Ni}_{2} \mathrm{P}$ Heterostructures for Efficient Electrocatalytic Water Splitting. ACS Appl. Mater. Interfaces 2018, 10, 4689-4696. [CrossRef]

18. Beygi, H.; Sajjadi, S.A. Magnetic properties of crystalline nickel and low phosphorus amorphous $\mathrm{Ni}_{1-\mathrm{x}} \mathrm{P}_{\mathrm{x}}$ nanoparticles. Mater. Chem. Phys. 2018, 204, 403-409. [CrossRef] 
19. Niemann, A.C.; Gooth, J.; Wu, S.-C.; Baessler, S.; Sergelius, P.; Huehne, R.; Rellinghaus, B.; Shekhar, C.; Suess, V.; Schmidt, M.; et al. Chiral magnetoresistance in the Weyl semimetal NbP. Sci. Rep. 2017, 7, 43394. [CrossRef] [PubMed]

20. Einaga, M.; Shimizu, K.; Hu, J.; Mao, Z.Q.; Politano, A. Resistivity of Weyl semimetals NbP and TaP under pressure. Phys. Status Solidi-Rapid Res. Lett. 2017, 11, 1700182. [CrossRef]

21. Ding, L.; Shu, Y.; Wang, A.; Zheng, M.; Li, L.; Wang, X.; Zhang, T. Preparation and catalytic performances of ternary phosphides NiCoP for hydrazine decomposition. Appl. Catal. A Gen. 2010, 385, 232-237. [CrossRef]

22. Oyama, S.T.; Gott, T.; Zhao, H.; Lee, Y.-K. Transition metal phosphide hydroprocessing catalysts: A review. Catal. Today 2009, 143, 94-107. [CrossRef]

23. Verma, S.; Baig, R.B.N.; Nadagouda, M.N.; Varma, R.S. Visible light mediated upgrading of biomass to biofuel. Green Chem. 2016, 18, 1327-1331. [CrossRef]

24. Stinner, C.; Prins, R.; Weber, T. Formation, Structure, and HDN Activity of Unsupported Molybdenum Phosphide. J. Catal. 2000, 191, 438-444. [CrossRef]

25. Song, L.; Zhang, S.; Ma, Q. Synthesis of an iron phosphide catalyst based on sulfides and hydrodesulfurization property. Chem. Eng. J. 2015, 281, 281-285. [CrossRef]

26. Abu, I.I.; Smith, K.J. HDN and HDS of model compounds and light gas oil derived from Athabasca bitumen using supported metal phosphide catalysts. Appl. Catal. A Gen. 2007, 328, 58-67. [CrossRef]

27. Wei, J.; Ni, Y.; Xiang, N.; Zhang, Y.; Ma, X. Urchin-like $\mathrm{Ni}_{\mathrm{x}} \mathrm{P}_{\mathrm{y}}$ hollow superstructures: Mild solvothermal synthesis and enhanced catalytic performance for the reduction of 4-nitrophenol. CrystEngComm 2014, 16, 2113-2118. [CrossRef]

28. Lu, D.; Yuan, F.; Ni, Y.; Wan, M.; Cheng, X. Phase-control synthesis and catalytic property of magnetic $\mathrm{Ni} @ \mathrm{Ni}_{\mathrm{x}} \mathrm{P}_{\mathrm{y}}$ core-shell microstructures. Mater. Res. Bull. 2018, 101, 215-222. [CrossRef]

29. Lu, D.; Ni, Y.; Wu, H.; Wang, M.; Sheng, E. Preparation and catalytic properties of porous CoP nanoflakes via a low-temperature phosphidation route. Crystengcomm 2016, 18, 5580-5587. [CrossRef]

30. Yan, L.; Cao, L.; Dai, P.; Gu, X.; Liu, D.; Li, L.; Wang, Y.; Zhao, X. Metal-Organic Frameworks Derived Nanotube of Nickel-Cobalt Bimetal Phosphides as Highly Efficient Electrocatalysts for Overall Water Splitting. Adv. Funct. Mater. 2017, 27, 1703455. [CrossRef]

31. Wang, X.; Li, X.; Liu, C.; Li, F.; Li, Y.; Zhao, J.; Liu, R.; Li, G. Metalloid $\mathrm{Ni}_{2} \mathrm{P}$ and its behavior for boosting the photocatalytic hydrogen evolution of $\mathrm{CaIn}_{2} \mathrm{~S}_{4}$. Int. J. Hydrog. Energy 2018, 43, 219-228. [CrossRef]

32. Xu, Y.; Tu, W.; Zhang, B.; Yin, S.; Huang, Y.; Kraft, M.; Xu, R. Nickel Nanoparticles Encapsulated in Few-Layer Nitrogen-Doped Graphene Derived from Metal-Organic Frameworks as Efficient Bifunctional Electrocatalysts for Overall Water Splitting. Adv. Mater. 2017, 29, 1605957. [CrossRef] [PubMed]

33. Politano, A.; Cattelan, M.; Boukhvalov, D.W.; Campi, D.; Cupolillo, A.; Agnoli, S.; Apostol, N.G.; Lacovig, P.; Lizzit, S.; Farias, D.; et al. Unveiling the Mechanisms Leading to H-2 Production Promoted by Water Decomposition on Epitaxial Graphene at Room Temperature. Acs Nano 2016, 10, 4543-4549. [CrossRef] [PubMed]

34. Zhong, Y.; Yin, L.; He, P.; Liu, W.; Wu, Z.; Wang, H. Surface Chemistry in Cobalt Phosphide-Stabilized Lithium-Sulfur Batteries. JACS 2018, 140, 1455-1459. [CrossRef]

35. Wu, H.; Chen, Z.; Zhang, J.; Wu, F.; Xiao, F.; Du, S.; He, C.; Wu, Y.; Ren, Z. Generalized Synthesis of Ultrathin Cobalt-Based Nanosheets from Metallophthalocyanine-Modulated Self-Assemblies for Complementary Water Electrolysis. Small 2018, 14, 1702896. [CrossRef] [PubMed]

36. Shi, Y.; Zhang, B. Engineering transition metal phosphide nanomaterials as highly active electrocatalysts for water splitting. Dalton Trans. 2017, 46, 16770-16773. [CrossRef] [PubMed]

37. Regmi, Y.N.; Roy, A.; King, L.A.; Cullen, D.A.; Meyer, H.M.; Goenaga, G.A.; Zawodzinski, T.A.; Labbé, N.; Chmely, S.C. Lattice Matched Carbide-Phosphide Composites with Superior Electrocatalytic Activity and Stability. Chem. Mater. 2017, 29, 9369-9377. [CrossRef]

38. Xu, Y.Z.; Yuan, C.Z.; Liu, Z.W.; Chen, X.P. In situ synthesis of NiSe@CoP core-shell nanowire arrays on nickel foam as a highly efficient and robust electrode for electrochemical hydrogen generation in both alkaline and acidic media. Catal. Sci. Technol. 2018, 8, 128-133. [CrossRef]

39. Bai, X.; Ren, Z.; Du, S.; Meng, H.; Wu, J.; Xue, Y.; Zhao, X.; Fu, H. In-situ structure reconstitution of $\mathrm{NiCo}_{2} \mathrm{P}_{\mathrm{X}}$ for enhanced electrochemical water oxidation. Sci. Bull. 2017, 62, 1510-1518. [CrossRef]

40. Stinner, C.; Prins, R.; Weber, T. Binary and Ternary Transition-Metal Phosphides as HDN Catalysts. J. Catal. 2001, 202, 187-194. [CrossRef] 
41. Sun, F.; Wu, W.; Wu, Z.; Guo, J.; Wei, Z.; Yang, Y.; Jiang, Z.; Tian, F.; Li, C. Dibenzothiophene hydrodesulfurization activity and surface sites of silica-supported $\mathrm{MoP}, \mathrm{Ni}_{2} \mathrm{P}$, and $\mathrm{NiMoP}$ catalysts. J. Catal. 2004, 228, 298-310. [CrossRef]

42. Wu, J.; Liu, W.; Xiang, X.; Sun, K.; Liu, F.; Cai, C.; Han, S.; Xie, Y.; Li, S.; Zu, X. From Ni(OH) 2 /Graphene composite to Ni@Graphene core-shell: A self-catalyzed epitaxial growth and enhanced activity for nitrophenol reduction. Carbon 2017, 117, 192-200. [CrossRef]

43. Yuan, F.; Ni, Y.; Zhang, L.; Ma, X.; Hong, J. Rod-Like $\mathrm{Co}_{2} \mathrm{P}$ Nanostructures: Improved Synthesis, Catalytic Property and Application in the Removal of Heavy Metal. J. Clust. Sci. 2013, 24, 1067-1080. [CrossRef]

44. Ghosh, S.K.; Mandal, M.; Kundu, S.; Nath, S.; Pal, T. Bimetallic Pt-Ni nanoparticles can catalyze reduction of aromatic nitro compounds by sodium borohydride in aqueous solution. Appl. Catal. A Gen. 2004, 268, 61-66. [CrossRef]

45. Houshen, L.; Yijing, L.; Shengqing, W. Water-soluble Au nanocages for enzyme-free $\mathrm{H}_{2} \mathrm{O}_{2}$ sensor and 4-nitrophenol reduction. CrystEngComm 2015, 17, 2368-2375.

46. Huang, X.; Qi, X.; Boey, F.; Zhang, H. Graphene-based composites. Chem. Soc. Rev. 2012, 41, 666-686. [CrossRef] [PubMed]

47. Hu, L.; Zhang, R.; Wei, L.; Zhang, F.; Chen, Q. Synthesis of FeCo nanocrystals encapsulated in nitrogen-doped graphene layers for use as highly efficient catalysts for reduction reactions. Nanoscale 2015, 7, 450-454. [CrossRef]

48. Zhang, J.; Hou, C.; Huang, H.; Zhang, L.; Jiang, Z.; Chen, G.; Jia, Y.; Kuang, Q.; Xie, Z.; Zheng, L. Surfactant-concentration-dependent shape evolution of Au-Pd alloy nanocrystals from rhombic dodecahedron to trisoctahedron and hexoctahedron. Small 2013, 9, 538-544. [CrossRef]

49. Zhu, X.Y.; Lv, Z.S.; Feng, J.J.; Yuan, P.X.; Zhang, L.; Chen, J.R.; Wang, A.J. Controlled fabrication of well-dispersed AgPd nanoclusters supported on reduced graphene oxide with highly enhanced catalytic properties towards 4-nitrophenol reduction. J. Colloid Interface Sci. 2018, 516, 355-363. [CrossRef]

50. Yan, Z.; Fu, L.; Zuo, X.; Yang, H. Green assembly of stable and uniform silver nanoparticles on 2D silica nanosheets for catalytic reduction of 4-nitrophenol. Appl. Catal. B 2018, 226, 23-30. [CrossRef]

51. Zhang, R.; Wang, X.; Yu, S.; Wen, T.; Zhu, X.; Yang, F.; Sun, X.; Wang, X.; Hu, W. Ternary $\mathrm{NiCo}_{2} \mathrm{P}_{\mathrm{x}} \mathrm{Nannowires}$ as pH-Universal Electrocatalysts for Highly Efficient Hydrogen Evolution Reaction. Adv. Mater. 2017, 29, 1605502. [CrossRef] [PubMed] 